\title{
Prevalence of anemia in pregnancy at booking: a retrospective study at a tertiary care centre in Lucknow India
}

\author{
Asma Nigar ${ }^{1 *}$, Ausaf Ahmad ${ }^{2}$ \\ ${ }^{1}$ Department of Obstetrics and Gynaecology, ${ }^{2}$ Department of Community Medicine, Integral Institute of Medical \\ Sciences and Research, Kursi Road, Lucknow, Uttar Pradesh, India
}

Received: 29 August 2020

Accepted: 06 October 2020

*Correspondence:

Dr. Asma Nigar,

E-mail: drasmanigar@gmail.com

Copyright: $\odot$ the author(s), publisher and licensee Medip Academy. This is an open-access article distributed under the terms of the Creative Commons Attribution Non-Commercial License, which permits unrestricted non-commercial use, distribution, and reproduction in any medium, provided the original work is properly cited.

\begin{abstract}
Background: Anemia in pregnancy is one of the most common nutritional deficiency disorders affecting the pregnant women in the developing countries. The aim of our study was to understand the prevalence of anemia among pregnant women, and factors associated with anemia.

Methods: It was a retrospective record based study conducted in pregnant women, attending antenatal clinic and emergency in the Department of Obstetrics and Gynecology at Integral Institute of Medical Sciences and Research, Luck now, Uttar Pradesh, India. Data from 422 pregnant women regarding pregnancy were collected from $1^{\text {st }}$ January 2018 to $30^{\text {th }}$ June 2018 by referring the records.

Results: Present study included 422 pregnant females in first, second and third trimester. In the present study, majority of the pregnant women belonged to the age group of 20-25 years (49.5\%) followed by age group of 26-30 years $(35.5 \%)$. The prevalence rate of anemia was found to be $57.6 \%$, with moderate anemia being the most common (44.8\%). Higher proportion of anemia was found in third trimester (75.3\%) followed by second trimester (16.5\%).

Conclusions: High prevalence (57.6\%) of anemia was observed in pregnant women. We are far away from achieving our target of Anemia Mukht Bharat by 2022. There is need to create awareness among females regarding ANC visits, birth spacing and iron and folic acid supplementation during pregnancy.
\end{abstract}

Keywords: Anemia, Antenatal care, Birth interval, Parity, Pregnancy

\section{INTRODUCTION}

Maternal anemia remains an important public health problem in under-developed and developing countries like India. Anemia during pregnancy is one of the most common nutritional deficiency disorder.

Anemia in pregnancy has been defined by WHO as a condition in which the hemoglobin concentration of a woman during pregnancy is $<11 \mathrm{~g} / \mathrm{dl}$. Nutritional anemia, specifically iron deficiency anemia (IDA) is the most common cause of anemia during pregnancy, globally affecting about 32 million women. ${ }^{1}$ As estimated by
WHO, prevalence of anemia is $14 \%$ in developed countries, $51 \%$ in developing countries, and $65-75 \%$ in India. ${ }^{2-3}$

In India, according to recent National Family Health Survey-4,(NFHS-4) the prevalence of anemia is estimated to be $50.3 \%$. There has been a reduction in the prevalence of anemia from 58.3 (NFHS-3) to 50.3\% (NFHS-4), there is not much difference in the prevalence of anemia reported in NFHS-2 $(49.7 \%)$ and NFHS-4 $(50.3 \%) .{ }^{4}$ India contributes to about $80 \%$ maternal deaths in South Asia as estimated by WHO. ${ }^{3}$ Anemia in pregnancy is defined (WHO) as a condition where 
hemoglobin concentration in blood is less than $11 \mathrm{~g} / \mathrm{dl}$. It is further classified into mild, moderate and severe. It is said to be mild when hemoglobin level is between 10 to $10.9 \mathrm{~g} / \mathrm{dl}$, moderate when it is between 7 to $9.9 \mathrm{~g} / \mathrm{dl}$ and severe when it is less than $7 \mathrm{~g} / \mathrm{dl} .^{5}$

Anemia has been found to be associated with conditions complicating pregnancy, such as abortions, premature births, postpartum hemorrhage (PPH) and low birth weight (LBW). Thus it is considered as one of the most common and preventable complications of pregnancy. Hence present study was undertaken to evaluate the prevalence of anemia among pregnant women, and to know factors associated with anemia.

\section{METHODS}

It was a retrospective record-based study conducted in the Department of Obstetrics and Gynecology at Integral Institute of medical sciences and research, Lucknow, Uttar Pradesh, India. Data regarding pregnancy from $1^{\text {st }}$ January 2018 and $30^{\text {th }}$ June 2018 were collected and analyzed. Data from 422 pregnant women who attended to ANC clinic or emergency from $1^{\text {st }}$ January 2018 to $30^{\text {th }}$ June 2018 were recorded.

\section{Inclusion criteria}

Pregnant women who attended antenatal clinic and emergency between were included in the study.

\section{Exclusion criteria}

Pregnant women with hemolytic anemia, anemia due to acute blood loss (APH), medical disorders like hypertension, diabetes, cardiac disease and chronic renal disease were excluded from the study.

\section{Data collection}

Data were retrieved from medical record department of the hospital using data extraction sheet after getting permission for conducting the study from concerned authorities. Data from 422 pregnant patients regarding pregnancy, from January 2018 to June 2018 over a period of 6 months were collected.

Details regarding, age, residence, religion, gravid, parity, educational status, occupation, and gestational age at time of registration were recorded. Hemoglobin level was taken from the case record and was classified as mild, moderate and severe based on WHO classification.

\section{Data analysis}

Data were analyzed using SPSS software version 20. Descriptive statistics was calculated using frequencies and percentages. Association was calculated using Chi square test wherever required.

\section{RESULTS}

The levels of hemoglobin used for classification of anemia in pregnant women as mild, moder-ate and severe anemia were those recommended by the WHO. Mild, moderate and severe anemia was defined as follows: Normal: $\mathrm{Hb}$ greater than $11.0 \mathrm{mg} / \mathrm{dl}$; Mild anemia: $\mathrm{Hb}$ $10.0 \mathrm{mg} / \mathrm{dl}-10.9 \mathrm{mg} / \mathrm{dl}$. Moderate anemia: $\mathrm{Hb} 7.0 \mathrm{mg} / \mathrm{dl}-$ $10.0 \mathrm{mg} / \mathrm{dl}$. Severe anemia: Hb less than $7 \mathrm{mg} / \mathrm{dl}$.

A total of 422 pregnant women were registered for ANC care. In the present study majority of the pregnant women belonged to the age group of $20-25$ years $(49.5 \%)$ followed by age group of 26-30 years (35.5\%).fifty six (13.3\%) pregnant women belonged to age group greater than 30 years. Minimum number of pregnant women were registered to age group of less than 20 years $(1.7 \%)$. (Table 1).

Table 1: Distribution of participants according to age.

\begin{tabular}{|lll|}
\hline Age & Number & Percentage \\
\hline$<\mathbf{2 0}$ years & 7 & 1.7 \\
\hline $\mathbf{2 0 - 2 5 y e a r s}$ & 209 & 49.5 \\
\hline $\mathbf{2 6 - 3 0}$ years & 150 & 35.5 \\
\hline$>\mathbf{3 0}$ years & 56 & 13.3 \\
\hline Total & 422 & 100.0 \\
\hline
\end{tabular}

As shown in Table 2, four hundred twenty-two (422) pregnant women were recruited for the study, out of which 138 (32.7\%) women were primigravida. In this study, as parity of women increases from 0 to 2 , percentage of pregnant women increases to $58.3 \%$. Minimum number of study subjects belonged to parity two or more.

\section{Table 2: Distribution of participants according to} parity.

\begin{tabular}{|lll|}
\hline Parity & Number & Percentage \\
\hline $\mathbf{0}$ & 138 & 32.7 \\
\hline $\mathbf{1 - 2}$ & 246 & 58.3 \\
\hline $\mathbf{2}$ & 38 & 9 \\
\hline Total & 422 & 100.0 \\
\hline
\end{tabular}

Present study classified 422 pregnant females as normal, mild, moderate and severe anemia. The prevalence rate of anemia was found $57.6 \%$ (243 out of 422 study subjects). Higher proportion of anemic pregnant women was found in moderate category $(44.8 \%)$ followed by mild category $(10.0 \%)$. Lowest percentage of anemic women were seen in severe category $(2.8 \%)$ as compared to other categories. (Table 3).

As shown in Table 4, four hundred twenty two (422) pregnant women were recruited for the study, out of which 179 women were non anemic. Proportion of anemic pregnant women were more in age group of 2025 years as compared to all age categories, and the 
proportion of anemic pregnant women was minimum in the age group less than 19 years while majority of anemic pregnant women were above 26 years of age. No statistically significant risk of anemia among age groups was observed. Out of total study subjects only 9.5\% anemic pregnant women be-longed to parity greater than two.

Table 3: Distribution of pregnant women according to degree of anemia.

\begin{tabular}{|lll|}
\hline $\begin{array}{l}\text { Classification of } \\
\text { anemia }\end{array}$ & Frequencies & Percentage \\
\hline Normal & 179 & 42.4 \\
\hline mild & 42 & 10.0 \\
\hline moderate & 189 & 44.8 \\
\hline severe & 12 & 2.8 \\
\hline total & 422 & 100.0 \\
\hline
\end{tabular}

It was also seen that among all anemic females $65.4 \%$ were Hindu compared to $34.6 \%$ females belonged to
Muslim females. This difference was found to be significant ( $\mathrm{p}$ value $<0.05$ ). Among the anemic pregnant women, $72.4 \%$ were rural. We also observed that maximum $73.7 \%$ females in anemic category were illiterate.93\% females among all females having anemia were housewife or working as agriculture workers.

Approximately similar percentage of anemic pregnant women were in booked and unbooked cat-egories. Present study included 422 pregnant females in first, second and third trimester. The proportion of anemia was found $57.6 \%$ (243 out of 422 study subjects). Higher proportion of anemia was found in women booked in third trimester $(75.3 \%)$ followed by second trimester $(16.5 \%)$. Lowest percentage of anemic women was in pregnant females booked in first trimester $(8.2 \%)$ as compared to other categories. The association between gestational age at booking and anemia in pregnancy was, however, not statistically significant (Table 4).

Table 4: Association of anaemia with different variables.

\begin{tabular}{|c|c|c|c|}
\hline Characteristics & Anemia absent (\%) & Anemia present (\%) & P value \\
\hline \multicolumn{4}{|l|}{ Age (in years) } \\
\hline$<19$ & $5(2.8)$ & $2(0.8)$ & \multirow{4}{*}{0.45} \\
\hline $20-25$ & $86(48.0)$ & $123(50.6)$ & \\
\hline 26-30 & $65(36.3)$ & $85(35.0)$ & \\
\hline$>\mathbf{3 0}$ & $23(12.8)$ & $33(13.6)$ & \\
\hline \multicolumn{4}{|l|}{ Parity } \\
\hline $\mathbf{0}$ & $62(34.6)$ & $76(31.3)$ & \multirow{3}{*}{0.747} \\
\hline $1-2$ & $102(57.0)$ & $144(59.3)$ & \\
\hline$>2$ & $15(8.4)$ & $23(9.5)$ & \\
\hline \multicolumn{4}{|l|}{ religion } \\
\hline Muslim & $79(44.1)$ & $84(34.6)$ & \multirow{2}{*}{0.046} \\
\hline Hindu & $100(55.9)$ & $159(65.4)$ & \\
\hline \multicolumn{4}{|l|}{ Residence } \\
\hline Rural & $135(75.4)$ & $176(72.4)$ & \multirow{2}{*}{0.497} \\
\hline Urban & $44(24.6)$ & $67(27.6)$ & \\
\hline \multicolumn{4}{|l|}{ Education } \\
\hline Illiterate & $143(79.9)$ & $179(73.7)$ & \multirow{4}{*}{0.523} \\
\hline Primary & $10(5.6)$ & $18(7.4)$ & \\
\hline Secondary & $23(12.8)$ & $40(16.5)$ & \\
\hline Graduate & $3(1.7)$ & $6(2.5)$ & \\
\hline \multicolumn{4}{|l|}{ occupation } \\
\hline Housewife /Agriculture & $169(94.4)$ & $226(93.0)$ & \multirow{2}{*}{0.559} \\
\hline employed & $10(5.6)$ & $17(7.0)$ & \\
\hline \multicolumn{4}{|l|}{ Booking status } \\
\hline Booked & $97(54.2)$ & $114(47.1)$ & \multirow{2}{*}{0.090} \\
\hline Unbooked & $82(45.8)$ & $128(52.9)$ & \\
\hline \multicolumn{4}{|l|}{ Gestational age } \\
\hline First trimester & $21(11.7)$ & $20(8.2)$ & \multirow{3}{*}{0.283} \\
\hline Second trimester & $22(12.3)$ & $40(16.5)$ & \\
\hline Third trimester & $136(76.0)$ & $183(75.3)$ & \\
\hline
\end{tabular}




\section{DISCUSSION}

Anemia is a known public health problem affecting mainly the developing countries, especially anemia in pregnancy. It has got deleterious effects not only to the health of the mother but also the outcome of the pregnancy, health of the baby, leading to increased maternal and perinatal morbidities.

Data from NFHS 2, 3 and 4 showed that about 50 percent of pregnant women in India are anemic. Among South Asian countries, India has the highest prevalence of anemia in pregnancy. ${ }^{6}$

Although, there was a reduction in the prevalence of anemia from 58.3 to 50.3 percent between NFHS 3 and 4 , there is not much difference in the prevalence of anemia in NFHS 4(50.3\%) and NFHS $2(49.7 \%){ }^{4}$

In our study, high prevalence of anemia (57.6\%) was observed. Among anemic females' moderate anemia was the most prevalent $(44.8 \%)$, followed by mild anemia $(10 \%)$. Severe anemia was seen in $(2.8 \%)$ pregnant females. Similar study conducted in Lucknow showed that overall prevalence of anemia was $73.1 \%$. Among them, moderate anemia was $47.6 \%$, mild was $43.6 \%$, and severe was $8.8 \% .^{7}$ Another study done by Bhargavi et al found that $52.73 \%, 40.97 \%$, and $6.28 \%$ of pregnant females were having mild, moderate and severe anemia respectively. ${ }^{8}$

Suryanarayana et al. conducted a study in Kolar district and showed prevalence of anemia to be $63 \%$ among pregnant women. ${ }^{9}$ In our study, maximum number of pregnant women were in the age group of 20 to 25 years (49.5\%), which is comparable with study by Sharma et al. ${ }^{10}$ Similar study by Mangla et al. in rural area of Haryana found maximum number of pregnant women in the age group of $20-29$ years and more than $70 \%$ of them were literates. ${ }^{11}$

Higher prevalence of anemia (58.3\%) seen in second gravid and $32.7 \%$ in primigravida pregnant women. Rajamouli et al also found higher prevalence of anemia in second gravida (43.3\%) compared to $38.8 \%$ in primigravida. This high prevalence of anemia in second gravid can be attributed to factors like close pregnancies, malnutrition, not taking prophylaxis doses of iron \& folic acid tablets. ${ }^{12}$ We observed that most cases of anemia were of moderate (44.8) \%, followed by mild anemia (10\%). Only $2.8 \%$ pregnant females were found to be severely anemic. These results were similar to NFHS 3 reports and study done by Agarwal et al where most common type of anemia was of moderate degree. ${ }^{10,13}$

Table 4 shows association of anemia with different variables like age, parity, religion, residence, educational status, occupation, booking status and gestational age at booking. We found that among all anemic females, maximum women were in 20-25 years of age and had parity of 1-2. We observed that among all anemic females, $65.4 \%$ were Hindu compared to $34.6 \%$ Muslim females. This difference was found to be significant. A high prevalence of anemia among Hindu women as compared to Muslim women was observed in the present study. It probably could be because of different dietary patterns like more preference to vegetarian food and food taboos that are more prevalent in Hindu religion. A study by Mishra et al found almost equal incidence of anemia in Hindu and Muslim females. ${ }^{7}$ Our study also showed that higher proportion of anemic pregnant women belonged to rural area.

Educational status of females plays an important role in the incidence of anemia which is reported to be higher among the illiterate women residing in a rural environment, as it was also observed in our study. Our results were similar to another study which found that anemia was found more common in illiterate rural women. ${ }^{14}$

The present study also found that $75.3 \%$ anemic women were in third trimester of pregnancy, which was similar to a study done in Ghaziabad were majority of pregnant women registered during third trimester $(49.7 \%)$ and only $35.8 \%$ of the pregnant women registered during first trimester. ${ }^{15}$

A study by Vindhya et al also did not find significant association of anemia with socio-demographic and obstetric variables. ${ }^{16}$

Funding: No funding sources

Conflict of interest: None declared

Ethical approval: The study was approved by the Institutional Ethics Committee

\section{REFERENCES}

1. WHO. Hemoglobin concentrations for the diagnosis of anemia and assessment of severity vitamin and mineral nutrition information system. Geneva World Health Organization, Available at http://www. who.int/vmnis/indicators/haemoglobin.pdf. Accessed on 12 July 2020.

2. DeMayor EM, Tegman A. Prevalence of anemia in the world, World Health Organization. 1998;38:30216.

3. Kalaivani K. Prevalence and consequences of anemia in pregnancy. Indian J Med Res. 2009;130:627-33.

4. NFHS-4, 2015-16. Rchiips.org; 2016. Available at: http:// rchiips .org /NFHS /pdf /NFHS4 /India.pdf. Accessed on 12 July 2020.

5. World Health Organization (WHO). The prevalence of Anemia in women: a tabulation of available information. Geneva, Switzerland: WHO; 1992. Available at $\mathrm{WHO} / \mathrm{MCH} / \mathrm{MSM} / 92.2$. Accessed on 12 July 2020. 
6. Kalaivani K, Ramachandran $\mathrm{P}$. Time trends in prevalence of anemia in pregnancy. Indian $\mathrm{J}$ Med Res. 2018;147(3):268-77.

7. Mishra S, Gupta P, Bhardwaj P, Sachan B, Srivastava JP, Mishra AN. Effect of antenatal services during pregnancy on prevalence of anemia amongst pregnant women in Lucknow. Indian J Med Sci. 2016;68(1):48-51

8. Vemulapalli B, Rao K. Prevalence of anemia among pregnant women of rural community in Vizianagram, North Coastal Andhra Pradesh, India. Asian J Med Sciences. 2014;5:44-9.

9. Suryanarayana R, Chandrappa M, Santhuram AN, Prathima S, Sheela SR. Prospective study on prevalence of anemia of pregnant women and its outcome. A community based study. J Family Med Prim Care. 2017;6:739-43.

10. Agarwal KN, Agarwal DK, Sharma A, Sharma K, Prasad K, Kalita MC, et al. Prevalence of anemia in pregnant and lactating women in India. Indian J Med Res. 2006;124:173-84.

11. Mangla M, Singla D. Prevalence of anemia among pregnant women in rural India: A longitudinal observational study. Int J Reprod Contracept Obstet Gynecol. 2016;5:3500-5.

12. Rajamouli J, Ravinder A, Reddy SCK, Pambi S. Study on prevalence of anemia among pregnant women attending antenatal clinic at Rural Health
Training Centre (RHTC) and Chalmeda Anand Rao Institute of Medical Sciences Teaching Hospital, Karimnagar, Telangana, India. Int J Contemp Med Res. 2016;3(8):55-8.

13. Mumbai International Institute of Population Sciences; 2007. National Family Health Survey-III (NFHS 3) 2005-06. Available at https://dhsprogram.com/pubs/pdf/frind3/frind3vol1andvol2.pdf. Accessed on 12 July 2020.

14. Gautam VP, Bansal Y. Prevalence of anemia in pregnant women and its socio demographic associate is a rural area of Delhi. Ind $\mathbf{J}$ Community Med. 2002;27(4):157-60.

15. Singh R, Chauhan R, Singh H, Bhatnager M, Idnani R, Singh GP. A situational analysis of antenatal services and delivery practices among pregnant women: A retrospective study in NCR, Ghaziabad, India. Indian J Prev Soc Med. 2013;44(1-2):108-12.

16. Vindhya J, Nath A, Srinivas P. Prevalence and risk factors of anemia among pregnant women attending a public-sector hospital in Bangalore, South India. J Family Med Prim Care. 2019;8(1):37-43.

Cite this article as: Nigar A, Ahmad A. Prevalence of anemia in pregnancy at booking: a retrospective study at a tertiary care centre in Lucknow India. Int $\mathbf{J}$ Reprod Contracept Obstet Gynecol 2020;9:4585-9. 